\title{
The Research of Shareholder Equity Option Gamble Base on the Corporate Control Right Distribution
}

\author{
Wei Lei ${ }^{1}$ \\ ${ }^{1}$ Southwestern University of Finance and Economics,, 611130
}

Key Words: Shapley value Model; Ownership right; Control right; Method

\begin{abstract}
We build shareholding allocation model based on the sharply value model application of corporate control right. Conclusion shows that, the distribution of corporate control right to determine proportion of shareholding is feasible, that reveal the path of the ownership mechanism of corporate shareholders especially controlling shareholder to arrange the optimal control right distribution and provides the basis exploration, it has practical value to corporate controller to manipulate corporate's equity and voting rules.
\end{abstract}

\section{Introduction}

The last century, Berle \& Means (1932) find American corporate equity financing in the capital market, which leading to dispersed ownership excessively, more small and medium investors hold the corporate's ownership and control right by management oppositely, the phenomenon was derived out the separation of ownership and control right. Corporate control right is directly related to the configuration level of corporate governance and resource allocation (Jensen \& Meckling, 1976; Jing Yu, 2009; Jun Zhou \& Shan Lu, 2011) is the core of corporate management system. At present, the measure of control right from the shareholders of corporate base on vote shares, some scholars argue that (Leech, 1987; Zingales , 1994; Ling An, Xing Liu \& Yixin Bai, 2008) the previous control right measure can't measure shareholders' power perfectly, because of two reasons, first, the mainstream method without considering the shareholders alliance of cooperation, however shareholders conspired is common in the listed corporate ; Second, the asymmetric characteristics of both from the separation of ownership and control right, which result less equity can gain greater control right. Therefore, the calculation of the mainstream method failed to reflect the controlling shareholder rights and how to effect in the process of decision-making in the corporation further on. Some scholars (Leech, 1987,1988; Zingales,1994) applied the political science research power league game of sharply value model to measure corporation control right. Based on the sharply value model to measure the shareholder power as began, reverse under the exploration in determining the distribution of corporate controller how to configure the shareholder's stake.

\section{Theoretical Review}

Berle \& Means (1932) argue that corporate control right as a development process, which can be divided into five categories: shareholder control, management control, absolute control, relative control \& the provisions of law. Blair (1995) defines corporate ownership right as the sum of residual income claims and corporate control right. Corporate ownership characteristics show that ownership exists in the process of exercising supervision and decision-making cost. The connotation of control is more like the combination about the use and disposal of function, for example the original separation of the corporate's ownership, shareholders have complete corporate's ownership, therefor, for obtain maximum profits, shareholders will have to reconfigure the corporate resources, they would be delivered part of dispose power to managers, Managers exercise power and feedback information to shareholders. Loss (1988) points out that the corporate control right is leading the corporate management and decision-making right, law is the foundation of control power operation, articles association and internal management norms. Cubbin \& Leech (1983) divided corporate right into the control source and control degree, the control source 
according to whether the management control corporate is divided into the internal control and external control, external control is different classification in accordance with controller. Control degree is measured from 0 to 1 continuous variable to the value of autonomy constitutionally, the autonomy is the controlling shareholder with purpose and is associated with voting rights.

Berle \& Means' simple classification if a shareholder own $20 \%$ of the total number to voting shares of corporate, moreover there is no shareholders exceed the shareholder and other stakeholders of the total shares scattered relatively, such companies are defined as relative control type, obey Berle \& Means' standard, some scholars reduced $20 \%$ to $10 \%$ of stock equity as controlling stake standards relatively. Mainstream research measure regard shareholder control degrees as shareholding ratio in combination with the right to vote proportion, such as two each accounted for $15 \%$ of shareholders united than $25 \%$ of a shareholder are more influential. With the deepening of the research, from the first big shareholder to expand into the top 10 shareholders of corporate research, which measure the ownership structure and control right distribution is more closely to the corporate actual operation.

Shapley value model is applied to research the control right began in the 1980s, Leech (1987, 1988) using Shapley value model calculate the UK corporate's shareholders right, Rydvist (1988) using Shapley value model inspection of the voting power of the Swedish corporate shareholders, Leech \& Leathy (1991), Zingales (1994), Robinson, Rumsey \& White (1995), respectively, they use Shapley value model analyzed for the British corporate, Italy and Canada corporate shareholder control right. Lin An, Xing Liu\& Yixin Bai (2008) adopt the Shapley value of Marine game model on large shareholder checks and balances and conspiring to research. Yingying Chang, Xingqiang Du (2013) by Marine game model of Shapley value calculation control of private listed companies in China.

\section{Equity arrangement model}

Previous studies applied Shapley model to measure the shareholder power (Rydvist, 1988; Leech \&Leathy, 1991; Zingales, 1994), not controlling shareholder arrangement of control rights of the corporate, the controlling shareholder has ability and motivation to the arrangement corporate control right to maximize their own interests. We try to establish inverse model derived according to the Shapley model of determined by the control shareholders and ownership range to vote right in the board of directors.

Hypothesis 1: each shareholder as to rational economic man, each shareholder to maximize their own interests as the premise;

Hypothesis 2: We define the number of all shareholders to ${ }^{N},{ }^{N_{i}}$ show the ${ }^{i}$ participant; ${ }^{S_{i}}$ said the $i$ shareholder's stake, equation as $\sum_{i}^{N} S_{i} \leq 1 ; A_{i}$ said shareholder control right value conferred by the measure of sharply power model, equation as $\sum_{i}^{N} A_{i}=1 ; R$ said the board of directors voting rules, the range of $R \in(0,1]$.

According to the Shapley value measure model of shareholder control right, we can get the $2^{N}-1$ league constraint with $\mathrm{N}$ shareholders participate in the combination, the $N_{i}$ participation shareholder's control right have constraint of $C_{i}=\frac{2^{N}}{2}$. For each shareholder could choose alliance or non-aligned to get the control right, if the shareholders control right can achieve greater benefits but alliance, show their own equity does not affect the resolution of the board, there are $S_{i} \prec R$. An alliance is very complicated, according to the logic of sharply value model, find the number of shareholders to participate in combination firstly, to find the number of key participants secondly, calculate the control right of the shareholders finally. So, we get $S_{i}$ in descending order, 
$S_{1}$ is the largest shareholder, the range have $i, j \in[1, N], i \neq j$, we can expressed $N_{i}$ shareholders to participate gamble of league combination as $Q=\left[\begin{array}{llll}P_{N}^{1} & P_{N}^{2} & \cdots & P_{N}^{N}\end{array}\right]_{\frac{P_{N}^{N}}{N} \times N}$, and found that while a lot of shareholders arrangement is different but the combination of equity ratio is same. Such as the same constraints with arrangement of $S_{1} S_{2}$ with $S_{2} S_{1}$, that have the same result, therefore the same constraints can be consolidated into $K=\left[\begin{array}{llll}C_{N}^{1} & C_{N}^{2} & \cdots & C_{N}^{N}\end{array}\right]_{C_{N}^{2} * N}$, we define as $C_{N}^{2} * N$ matrix, for example $A B C$ the three shareholders, for example, the participation matrix and constraint matrix of key participants:

The participation matrix $\left[\begin{array}{ccc}A B C & B A C & C B A \\ A C B & C A B & B C A\end{array}\right]_{2 \times 3}$ The constraint matrix $\left[\begin{array}{ccc}A & A B & A B C \\ B & A C & 0 \\ C & B C & 0\end{array}\right]_{3 \times 3}$

We prescribed 0 means no-constraint, the first column regard as the first layer of $\boldsymbol{P}_{N}^{1}$ arrangement, corresponding $C_{N}^{1}$ constraints; the first column regard as the second layer of $\boldsymbol{P}_{N}^{2}$ arrangement, corresponding $C_{N}^{2}$ constraint; so there have N column regard as the N layer of $P_{N}^{N}$ arrangement, corresponding to $C_{N}^{N}$ constraints in result.

Secondly, by weight of Shapley value (Shapley) model $r(s)=\frac{(s-1) !(N-s) !}{N !}$, we can know its control right calculated in the form of $N$ ! as the denominator of the fraction, which can deduced the number of shareholders combinations as equation $\pi=N * P_{N-1}^{N-1}=N$ ! , the key participants defined as $N_{i}$ and $\omega_{i}$ is the number of the occurrences, then $\omega_{i}$ is positive integer regard as $\omega_{i} \in(o, 1,2 \cdots N !)$, by the above we can obtain $A_{i}=\frac{\omega_{i}}{\pi}$, key participants $S_{i}$ to participate in the league game from left to right order as $Q_{i}$, in each position of the number $Q_{i}$ obtain $0 \leq T_{i} \leq \frac{P_{N}^{N}}{N}$, such as matrix $Q_{A}=\left[\begin{array}{lll}A B C & B A C & C B A \\ A C B & C A B & B C A\end{array}\right]$, The key participants $A_{i}$ appeared in the $T_{1}, T_{2}, T_{3}$ position, $B$ and $C$ can get the same conclusion, Further more we can draw $A_{i}$ for a particular form of scores with no random values, so there shall be $S_{i} \geq S_{j} \Rightarrow A_{i} \geq A_{j}$, the range of the first big shareholder control right expressed as $\max S_{i} \Rightarrow \max A_{i} \in\left[\frac{1}{N}, \frac{(N-1) P_{N}^{N}}{N}\right]$. Based on the above logic, we give measure range of $R$, which can be expressed as the combination of $N$ layer constraints, it can be a single layer of constraint or a multitier combination of the constraint, if a shareholder control right is smaller, indicates its portfolio constraints include more shareholders to gain control right of corporation, the combination of shareholders voting rights surpass the board decision rules $R$, if shareholders shareholding ratio is 0 ,indicates its participation in any of $C_{N}^{2} * N$ constraints cannot gain control right, manifest the combination of shareholders holding is inferior to the board decision rules $R$. So, allocation of control right measure to use $R$ will be shown into the following form:

The number $\mathrm{M}$ of $\mathrm{N}$ participants have share the control right, there are $N-M=X$ of control right is 0 . 
(1)if $M$ is 1, and the $N_{i}$ shareholder non-aligned, then its control right can affect the decision of the board, and the other shareholders are not able to pose a threat to the $N_{i}$ shareholder through vote right, there are $S_{i} \geq R$, The key participants $S_{i}$ have the number of each position $T_{i}=\frac{P_{N}^{N}}{N}$, There are $\sum_{i=1}^{N-1} S_{j} \prec R, j \neq i$, then can draw a conclusion
$\forall A_{i}=1 \Rightarrow\left[\sum_{j=1}^{N} S_{j} \prec R \leq S_{i}, j \neq i\right]$, The solution to the board voting rules is $R$.

(2)If $M \leq N$, has the control right $A_{i}=\frac{\omega_{i}}{\pi}=\frac{N !}{M N !}=\frac{1}{M}$, we ordered $S_{i} i \in[1, N]$, if there is control right of 0 sometimes, can get to know $\forall A_{i} \leq \frac{1}{2}, j \in[2, M-1], l \in[M, N]$, because shareholders divide equally the control right that the constraint is only produced in this layer, if this level can't achieve divide equally the control right will be the next layer circulation until the ${ }^{N}$ layer, and any combination of $l \in[M, N]$ cannot obtained the control right, all above can expression:

$\left[\begin{array}{l}\forall C_{N}^{1} \prec R \\ \forall C_{j}^{2} \geq R \\ \forall\left(C_{j}^{j-1}+C_{l}^{1}\right) \prec R\end{array}\right] \cup\left[\begin{array}{l}\forall C_{N}^{2} \prec R \\ \forall C_{j}^{3} \geq R \\ \forall\left(C_{j}^{j-1}+C_{l}^{1}\right) \prec R\end{array}\right] \cdots \cup\left[\begin{array}{l}\forall C_{N}^{M-2} \prec R \\ \forall C_{N}^{M-1} \geq R \\ \forall\left(C_{j}^{j-1}+C_{l}^{1}\right) \prec R\end{array}\right] \cdots \cup\left[\begin{array}{l}\forall C_{N}^{N} \geq R \\ C_{N}^{M-1} \geq R \\ \forall C_{N}^{N-1} \prec R\end{array}\right] \Rightarrow R_{2} \cup R_{3} \cdots R_{N}$

There is no zero has, $\left[\begin{array}{l}\forall C_{N}^{1} \prec R \\ \forall C_{N}^{2} \geq R\end{array}\right] \cup \cdots\left[\begin{array}{l}\forall C_{N}^{i-1} \prec R \\ \forall C_{N}^{i} \geq R\end{array}\right] \cdots \cup\left[\begin{array}{l}\forall C_{N}^{N-1} \prec R \\ \forall C_{N}^{N} \geq R\end{array}\right] \Rightarrow R_{2} \cup R_{3} \cdots R_{N}$

According to the above formula we can calculate voting rules $R$ of the board, if the combination paradox within scope of $R$, there are no solution.

(2) Control right doesn't divide equally. we ordered $S_{i}$ in $i \in[1, N]$, We draw a conclusion that

the key to largest shareholder participation frequency $\omega_{i}$ is even, according to frequency of key participants $S_{i}$ in each position for $\frac{\boldsymbol{P}_{N}^{N}}{N}$, there are two conditions.

(1) If exist shareholder control right is zero, and others control right are 0 since after the $\mathrm{M}$ shareholders, there are ${ }^{M \in[M, N]}, i \in[1,2, \cdots J, \cdots M, \cdots N], j \in[1, M-1], T_{i}^{M}=0$

$S_{M}$ each key in position are not established.

(2)If no shareholder control right is 0 , according to the key for shareholders to participate in the position control of size ${ }^{T_{i}}$ counting from left to right, until meet the demands given by control of $\omega_{i}$, for the ${ }^{N_{i}}$ participants constraint combinations can be expressed as: 
$\left[\begin{array}{c}\text { (1) } \forall P_{N}^{1} \prec R \\ \text { (2) }\left\{\begin{array}{l}P_{N-i}^{1}+P_{i}^{i} \geq R \\ P_{N-i}^{1}+P_{i}^{i} \prec R\end{array}\right. \\ \text { (3) }\left\{\begin{array}{l}P_{N-i}^{2}+P_{i}^{i} \geq R \\ P_{N-i}^{2}+P_{i}^{i} \prec R \\ \vdots\end{array}\right. \\ \text { (N) }\left\{\begin{array}{l}P_{N-i}^{N-i}+P_{i}^{i} \geq R \\ P_{N-i}^{N-i}+P_{i}^{i} \prec R\end{array}\right]\end{array}\right]\left[\begin{array}{c}\text { (1) } \forall P_{N}^{2} \prec R \\ \text { (2) }\left\{\begin{array}{l}P_{N-i}^{3}+P_{i}^{i} \geq R \\ P_{N-i}^{3}+P_{i}^{i} \prec R\end{array}\right. \\ \text { (3) }\left\{\begin{array}{l}P_{N-i}^{4}+P_{i}^{i} \geq R \\ P_{N-i}^{4}+P_{i}^{i} \prec R \\ \vdots\end{array}\right. \\ (N-1)\left\{\begin{array}{l}P_{N-i}^{N-i}+P_{i}^{i} \geq R \\ P_{N-i}^{N-i}+P_{i}^{i} \prec R\end{array}\right]\end{array}\right] \cup\left[\begin{array}{l}P_{N-i}^{N-i}+P_{i}^{i} \geq R \\ P_{N-i}^{N-i}+P_{i}^{i} \prec R\end{array}\right] \Rightarrow R_{2} \cup R_{3} \cup \cdots R_{N}$

According to constraint matrix $K$, we can obtain solution of $R$, if the combination paradox within scope of $R$, there are no solution.

\section{Conclusion and Limitations}

We calculation the principle of Shapley value model to measure the shareholder choice of the stock equity distribution of corporate control right, construction the measure of equity arrangements model pioneeringly. But the minority shareholders control right measure of Shapley value model is simpler, and more participants in the consequences calculation is difficult, this paper faced the same problem of the model of with excessive participation result computing complex, for this problem we will be perfected in the subsequent research.

\section{Acknowledgment}

Supported by General Program of the National Natural Science Foundation of China (Grant No. 71572149)

\section{References:}

[1] A. A. Berle, G.C.Means. The Modern Corporation and Private Property, Harccurt, Brace and Wcrld, Inc,1932.

[2] Leech Dennis. Ownership concentration and the theory of the firm: a simple game-theoretic approach [J]. The Journal of Industrial Economics,1987,35(7):225 239

[3] Leech Dennis. Computing power indices for large voting games[J] Management Science, 2003, 49(6):831 837

[4] Cubbin John, Leech Dennis. The effect of shareholding dispersion on the degree of control in British companies: theory and evidence [J]. Economic Journal,1983,35(3):351 369

[5] Miluor J W, Shapley L S. Value of Large Games II :oceaiuc games[J].Mathematics of Operations Research.1978 3(4):290 307.

[6] Dennis Leech, John Leahy. J Leahy. Ownership Structure, Control Type Classifications and the Performance of Large British Companies[J].The Economic Journal,1991,101(409):1418 1437. 